\title{
Communication Attitude of Slovenian Preschool Children who do and do not Stutter
}

Article · January 2016

DOI: $10.4172 / 2472-5005.1000124$

CITATIONS

0

2 authors:

\section{Jerneja Novšak Brce}

University of Ljubljana

4 PUBLICATIONS 0 CITATIONS

SEE PROFILE
READS

26

Some of the authors of this publication are also working on these related projects:

Project

I believe you are from Italy? The Italian BAB for children who stutter should soon be published by Erickson. Do you work in the area of aphasia? View project

Investigation of speech-associated attitude among Slovenian children who stutter View project 


\title{
Journal of Speech Pathology \& Therapy
}

\section{Communication Attitude of Slovenian Preschool Children who do and do not Stutter}

\author{
Jerneja Novšak Brce ${ }^{1^{*}}$ and Martine Vanryckeghem ${ }^{2}$ \\ ${ }^{1}$ Faculty of Education, University of Ljubljana, Slovenia \\ ${ }^{2}$ University of Central Florida, United States
}

*Corresponding author: Jerneja Novšak Brce, Department of Special and Rehabilitation Pedagogy, University of Ljubljana, Slovenia, Tel: +386 1589 22 45; E-mail: jerneja.novsak@pef.uni-lj.si

Received date: October 27, 2016, Accepted date: January 21, 2017, Published date: January 28, 2017

Copyright: (c) 2017 Brce JN, et al. This is an open-access article distributed under the terms of the Creative Commons Attribution License, which permits unrestricted use, distribution, and reproduction in any medium, provided the original author and source are credited.

\begin{abstract}
Objective: The aim of this paper was to investigate the communication attitude of Slovenian preschool children who stutter by means of the Communication Attitude Test for Preschool and Kindergarten Children who Stutter (KiddyCAT), and to determine whether differences in communication attitude existed among preschool children who stutter, and their peers who are fluent speakers. In addition, the test's discriminant value, its internal reliability and the factors underpinning the Slovenian version of the KiddyCAT were explored.
\end{abstract}

Methods and Procedure: Data were gathered on a normative sample of 49 preschool children who stutter and 74 who do not stutter. The children were divided into two subgroups according to age: a "younger" ( 3 to 4,4 years old) and "older" (4,5 to 6 years old) group.

Outcomes and Results: Results showed that preschool children who stutter scored statistically significantly higher on the KiddyCAT than preschool children who do not stutter. The effect size was large. A mean increase in scores among the preschool children who stutter was observed, but was not statistically significant. An opposite observation, again not significant, was made for preschool children who do not stutter. Also gender did not affect the test results. The test is internally reliable and has construct validity.

Conclusion and Implications: The KiddyCAT is a useful tool for early detection of negative communication attitude of preschool children who stutter and helps in targeting cognitive-related stuttering intervention goals.

Keywords: KiddyCAT; Communication attitude; Stuttering; Stammering; Preschool children; Cognition; Speech-associated belief

\section{Background}

Researchers have documented that a statistically significant difference in communication attitude exists when comparing adults, school-age children and preschool children who stutter to their peers who speak fluently [1-6]. Adults and school-age children who stutter show statistically significantly more negative speech-related attitude than their normally fluent peers [1,2,4,5,7-9]. A statistically significant difference in the scores on the Communication Attitude Test (CAT) between the six-year-old children who stutter (CWS) and those whose speech is fluent (CWNS), led the researchers to hypothesize that the presence of a difference in communication attitude before the age of six was very likely [4]. The fact that children as young as age three years perceive the difference between fluent and non-fluent speech $[10,11]$, and indicate a preference of a fluent communication partner over a dysfluent one, already pointed to the presence of awareness of stuttering at this young age. These data, together with the fact that a negative belief surrounding communication among CWS is already present at the age of six and becomes increasingly more negative with age [4] highlight the impact that negative communication attitude can have on CWS. They indicate the need to assess communication attitude in preschool children whose fluency is problematic and, by extension, when needed, to address attitude change in treatment in order to move from a negative self-image and mal-attitude to a more positive belief system [6].

Vanryckeghem and Brutten [6] designed a Communication Attitude Test for Preschool and Kindergarten Children who Stutter, or KiddyCAT, specifically to investigate the presence, or absence, of a negative speech-related belief by means of self-report. This instrument employs verbal statements to gauge the communication attitude of preschoolers between the age of three and six years. Since its first development [12], the KiddyCAT has proven to be a reliable, valid and stable instrument. By means of factor analysis, Clark et al. [13] stipulated that all twelve KiddyCAT items are based on one single factor: "speech difficulty", and that their sample of CWS and CWNS responded differently to the underlying construct of this self-report test. Vanryckeghem, De Niels and Vanrobaeys' [14] test-retest reliability results indicated that, for the CWS, the KiddyCAT test-retest reliability was high $(\mathrm{r}=.90)$ and significant $(\mathrm{p}=.000)$. For the sample of CWNS a moderate but significant $(\mathrm{r}=.67 ; \mathrm{p}=.000)$ correlation was found between the first and second test scores. High and significant test-retest reliability (CWS: $\mathrm{r}=.953, \mathrm{p}=.000$, CWNS: $\mathrm{r}=.985, \mathrm{p}=.000$ ) was also found by Novšak Brce and colleagues [15].

Based on repeated findings of cross-cultural investigations that the KiddyCAT scores of CWS are statistically significantly higher compared to those of CWNS $[6,12,13,16-18]$, the data not only 
Page 2 of 5

indicate that children age three and older are aware of their fluency or dysfluency, but that CWS also think negatively about their speech. The present study's aim was to explore whether or not the documented negative belief system among preschool CWS also holds-up for Slovenian preschoolers. In order to test this premise, a Slovenian version of the KiddyCAT was used as diagnostic tool.

\section{Aim}

In Slovenia, no instrument for the assessment of speech-associated attitude among CWS exists. It was thus the aim of the present research study to adopt and translate the KiddyCAT into Slovenian and to obtain data for the Slovenian population. The goal was (a) to determine if a difference in communication attitude exists between CWS and CWNS, (b) to establish the discriminant value of the test, (c) to investigate if age and gender have an influence on the test scores, (d) to verify if the KiddyCAT-SLO is internally reliable, and e) to evaluate construct validity by means of factor analysis.

\section{Methods}

\section{Participants}

The participants in this study were 49 preschoolers who stutter (32 boys, 17 girls) and 74 preschoolers who do not stutter (39 boys, 35 girls), between the age of 3 and 6 . The mean age for the CWS sample was 55.01 months $(S D=9.99)$, it was 55.20 months $(S D=9.92)$ for the CWNS group. CWS came from three centers (Institute for the Deaf and Hard of Hearing in Ljubljana, Center for Hearing and Speech in Maribor, and Center for Speech and Hearing in Portorož), covering the different urban and rural regions of Slovenia. The onset of their stuttering reportedly took place at least six months prior to the administration of the KiddyCAT and occurred during their initial fluency assessment. None of the children had prior treatment for stuttering or any other speech or language disorder. As indicated in the parent questionnaire and verified by the multi-disciplinary team in the three centers (including a pediatrician, psychologist, speech-language pathologist), these children did not have any other problems aside from stuttering.

CWNS came from different nursery schools in the same three areas in Slovenia. Information about the absence of a speech, language, hearing, developmental, neurological disorder and a possible family history of stuttering was investigated by means of a parent survey and confirmed by the nursery school teacher and school records. All children were native Slovenian speakers.

\section{Materials and Procedure}

The KiddyCAT@ - Communication Attitude Test for Preschool and Kindergarten Children who Stutter [6], translated into Slovene by the senior researcher [15], a 12-item self-report test which directly assesses the communication attitude of preschoolers, was used in this investigation. The preschoolers were asked to respond with 'yes' or 'no' to 12 questions about what they think about their talking (e.g "Is talking hard for you?", "Do mom and dad think that you speak well?”). Answers that express a negative communication attitude, are given a score of 1 . A response is scored as zero when it indicates positive thinking. The more negative the communication attitude is, the higher the test score. Thus, the range of scores can span between zero and 12.
In order to make an accurate translation and adaptation of the original KiddyCAT-SLO, the Slovenian researcher was involved in back translation with the test authors. A translation as close as possible to the original test was aimed for, however, cultural appropriateness was taken into consideration in the final test adaptation.

The children were individually assessed in a quiet room, CWNS by the Slovenian researcher and CWS by four fluency specialists, who came from the same three areas of Slovenia where the CWS resided. The fluency specialists were trained in the administration of the test procedure by the senior researcher. According to the test protocol instructions, the speech-language therapist explained the procedure to the child and gave him/her two practice questions to ensure that the child understood the instructions. After that, the researcher proceeded to the 12 statements. To facilitate a child's participation, a play activity was used; for each "yes" or "no" answer the child moved a frog one square forward. A prize was obtained when he/she arrived at the last (12th) square. If a child responded to the KiddyCAT statements uniquely with "yes" or "no", a "dummy" question (e.g. Can you walk/Can you fly?) was asked after items 5 and 10.

Because some of the KiddyCAT items contain the terms difficult and easy, it is important to know whether or not the child understands these terms before administering the KiddyCAT. The test administrator determined knowledge of these terms by means of a practical probe: having two jars containing an object, one which opened easily and one which was difficult to open. Upon trying to open both jars, the child was asked if it was easy or difficult to open the container. None of the children had difficulty understanding these terms.

\section{Results and Discussion}

\section{Comparative data: CWS and CWNS}

As can be seen in Table 1, the KiddyCAT scores for a representative sample of preschool CWNS ranged from 0 to 5 , out of a possible maximum score of 12 . The mean score for the group of CWNS was .81 $(\mathrm{SD}=1.51)$. The modal score was 0 . As shown in Figure 1, the scores for the CWNS fall in the lower half of the distribution. For the preschool CWS, the KiddyCAT scores ranged 0 to 10 with a mode of 5 . The mean score for CWS was $5.16(\mathrm{SD}=2.98)$. As indicated in Figure 1, the scores of CWS are more widely distributed compared to those of their normally fluent peers. Importantly, the between-group difference in the mean KiddyCAT score proved to be statistically significant $(\mathrm{F}=114.136, \mathrm{p}=.000)$ and the effect size large (Cohen $\left.\eta^{2}=.485\right)$. Thus, preschoolers who stutter reported significantly more negative communication attitude compared to children who speak fluently.

\begin{tabular}{|l|l|l|}
\hline & CWS $(n=49)$ & CWNS $(n=74)$ \\
\hline Mean (M) & 5.16 & 0.81 \\
\hline Std Deviation (SD) & 2.98 & 1.51 \\
\hline Mode & 5 & 0 \\
\hline Minimum & 0 & 0 \\
\hline Maximum & 10 & 5 \\
\hline
\end{tabular}

Table1: Measures of Central Tendency and Variation for CWS and CWNS on the KiddyCAT. 
Page 3 of 5

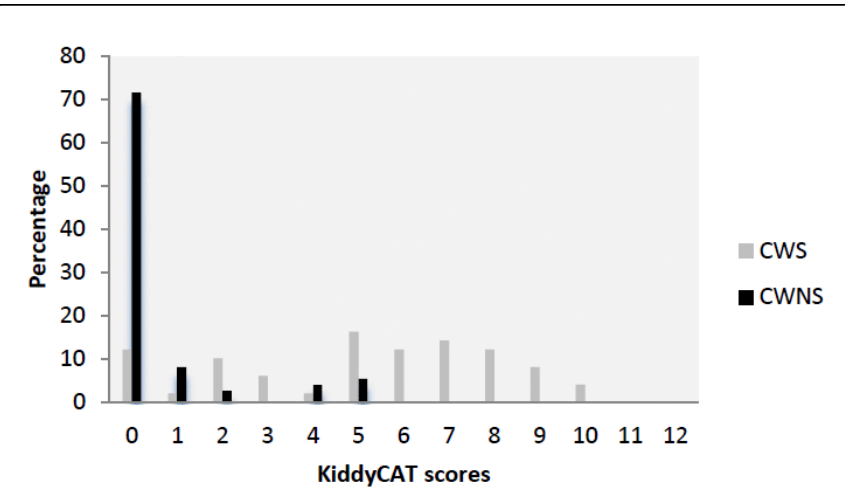

Figure 1: Distribution, in percentage, of KiddyCAT scores for CWS and CWNS

In the Vanryckeghem and Brutten [6] study, the mean CWS score was $4.36(\mathrm{SD}=2.78)$, and $1.79(\mathrm{SD}=1.78)$ for CWNS. Another USAbased study [13] revealed a mean score for the experimental group of $4.42(\mathrm{SD}=2.53)$ and $2.61(\mathrm{SD}=2.20)$ for the control group.

Węsierska, Vanryckeghem, Jeziorczak and Wilk [19] obtained a similar mean score for their group of Polish CWS $(4.6 \overline{0,} \mathrm{SD}=2.46)$. The mean score for the control group was somewhat lower (1.47, SD=1.05). Vanryckeghem and Brutten [16] found an average KiddyCAT score of $3.47(\mathrm{SD}=2.77)$ and $1.15 \overline{(\mathrm{SD}}=1.22)$ for the CWS and CWNS, respectively. In all studies, CWS reported a speech-related attitude that was statistically significantly higher compared to that of CWNS.

Comparison of the current results to those mentioned above, lead to the conclusion that Slovenian preschoolers who stutter, on average, report somewhat more in the way of negative communication attitude compared to the results of the above mentioned investigations. Replication studies will need to shed light on whether or not the reason for this slight difference may be culturally determined. From the results it can also be concluded that the Slovenian preschool children who speak fluently, on average, indicate slightly less in the way of negative communication attitude compared to preschoolers in the US $[6,13]$, Poland [19] and Belgium [14,16]. Nevertheless, what the current study has in common with the other internationally-based studies is that the between-group difference was statistically significant, and that, once more, it can be confirmed that CWS develop a negative belief about their speech soon after onset of stuttering.

\begin{tabular}{|c|c|c|c|c|}
\hline & Group & \multicolumn{2}{|c|}{$\begin{array}{c}\text { Predicted Group } \\
\text { Membership }\end{array}$} & Total \\
\hline & & CWS & CWNS & \\
\hline \multirow{2}{*}{ Original Count } & CWS & 37 & 12 & 49 \\
\cline { 2 - 5 } & CWNS & 6 & 68 & 74 \\
\hline \multirow{2}{*}{$\%$} & CWS & 75.5 & 24.5 & 100 \\
\cline { 2 - 5 } & CWNS & 8.1 & 91.9 & 100 \\
\hline
\end{tabular}

Table 2: Discriminant Analysis Classification Results for the KiddyCAT

Discriminant Function analysis was used to determine if the KiddyCAT successfully distinguishes between preschool CWS and
CWNS. The canonical correlation of 0.71 establishes that the KiddyCAT discriminates well between the two groups. Table 2 indicates that $75.5 \%$ of CWS and $91.9 \%$ of the preschool CWNS were correctly classified. Eight-five percent (85.4\%) of the original grouped cases were correctly classified. From these data, it can be concluded that the KiddyCAT has good discriminatory power.

\section{Communication attitude and age}

CWS and CWNS were divided into a "younger" (age 3 to 4.4) and "older" (age 4.5 to 6) group, in order to determine whether communication attitude changes with age. Table 3 shows that younger CWS as well as CWNS had a descriptively lower mean KiddyCAT score than the older children in their respective groups. For neither group this numeric difference was statistically significant $(\mathrm{F}=.108, \mathrm{p}=$. 743 for CWS; $\mathrm{F}=.003, \mathrm{p}=.954$ for CWNS). Thus, although negative communication attitude in CWS increases with age, the KiddyCAT score of younger and older CWS did not differ to a statistically significant extent.

\begin{tabular}{|c|c|c|c|c|}
\hline & \multicolumn{2}{|c|}{ CWS $(n=49)$} & \multicolumn{2}{c|}{ CWNS $(n=74)$} \\
\hline & Younger $(n=25)$ & Older $(n=24)$ & Younger $(n=35)$ & Older $(n=39)$ \\
\hline Mean & 4.64 & 5.71 & 0.74 & 0.87 \\
\hline SD & 3.25 & 2.61 & 1.59 & 1.47 \\
\hline
\end{tabular}

Table 3: Means and Standard Deviations of Younger and Older CWS and CWNS on the KiddyCAT

The obtained results are consistent with the results of other studies. Although Vanryckeghem and Brutten [6] found that the mean KiddyCAT score of CWS numerically somewhat decreased with age, the difference was not statistically significant $(\mathrm{F}=1.388, \mathrm{p}=0.245)$, a finding that is consistent with that reported by Clark et al. [13] $(\mathrm{U}=172.5, \mathrm{p}=.379)$. Neither was a statistically significant difference in communication attitude between younger and older preschool CWS found in studies of Węsierska, Vanryckeghem, Jeziorczak and Wilk [19], and Węsierska and Vanryckeghem [17]. In the Vanryckeghem and Brutten [16] investigation with a Dutch version of the KiddyCAT, the younger and older CWS had an equal score. However, this time, among the CWNS, the older children (.91) scored statistically significantly lower than the younger ones (1.45). In general, care needs to be taken when interpreting the results, given the small number of participants in each subgroup.

The current results are also in line with those of studies on communication attitude in school-age children [4,6,8]. Among schoolage CWS, communication attitude becomes more negative with age. Stokke Guttormsen, Kefalianos and Naess [18], in their meta-analytic review of differences in communication attitude in CWS and CWNS, found that the effect size across studies became larger when the mean age in the sample increased, indicating that larger effect sizes are reported in studies with older school-age children, compared to effect sizes reported in the majority of studies examining preschool children.

\section{Communication attitude and gender}

A gender analysis, shown in Table 4, documents that the KiddyCAT scores of preschool children were not influenced by gender. Although the boys scored descriptively higher than the girls, this gender difference was not statistically significant for either group (CWS: $F=$. 
Page 4 of 5

335, $\mathrm{p}=.566$, Cohen $\eta^{2}=.007$ and CWNS: $\mathrm{F}=.132, \mathrm{p}=.717$, Cohen $\eta^{2}=$ 017).

\begin{tabular}{|c|c|c|c|c|}
\hline & \multicolumn{2}{|c|}{ Boys $(\mathrm{n}=71)$} & \multicolumn{2}{c|}{ Girls $(\mathrm{n}=52)$} \\
\hline & CWS & CWNS & CWS & CWNS \\
\hline Mean & 5.34 & 0.87 & 4.82 & 0.74 \\
\hline SD & 2.87 & 1.47 & 3.23 & 1.58 \\
\hline
\end{tabular}

Table 4: Means and Standard Deviations of CWS and CWNS boys and girls on the KiddyCAT

As expected, there was a statistically significant difference between the boys in the experimental compared to the control group ( $\mathrm{F}=71.850$, $\mathrm{p}=.000$, Cohen $\eta^{2}=.510$ ), and girls in the CWS versus CWNS group $\left(\mathrm{F}=37.930, \mathrm{p}=.000\right.$, Cohen $\left.\eta^{2}=.431\right)$.

As found in other studies, gender does not seem to affect the result of the KiddyCAT. The current findings are in agreement with those found by Clark et al. [13], Węsierska and Vanryckeghem [17], Vanryckeghem and Brutten [16], and Vanryckeghem, De Niels and Vanrobaeys [14], who also failed to find significant within-group differences in communication attitude according to gender. All research studies did show significant between-group gender differences.

\section{Internal reliability}

To determine the internal consistency of the KiddyCAT, a Cronbach alpha coefficient was calculated. The resulting reliability coefficient was .73 for both groups, which indicates that the Slovenian KiddyCAT is a reliable tool for assessing communication attitude in preschool children. Moreover, all items correlated statistically significantly with the total score for CWS and CWNS and each item was capable of differentiating both groups.

The described results are comparable with those of KiddyCAT investigations in the USA, where the obtained Cronbach's coefficient was .75 for CWS, and .72 for CWNS [12], and .72 for CWS and .75 for CWNS [6]. A Cronbach a coefficient of .71 was obtained for both groups in a Polish study [17] and a .75 and .70 for CWS and CWNS, respectively, in a Belgian and Netherlands-based investigation [16].

\section{Construct validity}

Construct validity was verified by means of factor analysis. The Principal Component with Varimax rotation analysis revealed three factors with eigenvalues greater than 1, which together explains $69.73 \%$ of the variance for the CWS' data. The first factor, accounting for $39.15 \%$ of the variance, brings together statements surrounding difficulty with saying one's name and words. The second factor, which explains $17.24 \%$, includes items that relate to the communication partner (e.g. difficulty when speaking with other people). The third factor explains $13.34 \%$ of variance and relates to the fact that speaking is difficult.

Comparison of the current data with those by Clark et al. [13] differ somewhat in the extent that Clark and colleagues identified one underlying dimension of the KiddyCAT for CWS: speech disruption, which explained $28.18 \%$ of the variance. The current data's resulting three dimensions explained a much larger variance, close to $70 \%$. Nevertheless, the resulting factors are much in agreement with the
Clark et al. [13] results, though more specific, to encompass speech difficulty because of difficult words or names, and because of the communicative partner.

\section{Conclusions}

The present research data confirm that the KiddyCAT-SLO is capable of differentiating CWS from CWNS based on their communication attitude, as has been documented through investigations in other countries $[6,13,16,17,19]$. The current results confirm that the KiddyCAT has construct validity and is an internally reliable instrument that distinguishes the communication attitude of CWS from CWNS to a statistically significant extent. The data also substantiate that young CWS, as a group, have already formed a negative communication attitude close to the onset of stuttering. Research data are abundant indicating that this negative speechassociated belief does not improve as children move into the schoolage years, adolescence and adulthood, to the contrary $[2,4,5,8,9,20,21,22]$. Having knowledge of the negative communication attitude present in preschool children is of great importance for clinical practice. This because, if a negative belief system is found to exist, it needs to be addressed early on during treatment, given the above mentioned data indicating that a negative speech-related attitude only increases as individuals who stutter get older. On the basis of the KiddyCAT results, as part of a larger multi-modal assessment, stuttering treatment targets which focus on addressing negative communication attitude can be identified.

\section{References}

1. Andrews G, Cutler J (1974) Stuttering therapy: the relation between changes in symptom level and attitudes. J Speech Hear Disord 39: 312-319.

2. Erickson RL (1969) Assessing communication attitudes among stutterers. J Speech Hear Res 12: 711-724.

3. Mclure J, Yaruss S (2003) Stuttering survey suggests success of attitudechanging treatment. ASHA Leader. 8: 19.

4. Vanryckeghem M, Brutten G (1997) The speech-associated attitude of children who do and do not stutter and the differential effect of age. Am J Speech Lang Pathol. 6: 67-73.

5. Vanryckeghem M, Brutten G (2001) The behavior assessment battery: A research pathway. J Fluency Disord. 26: 349-352.

6. Vanryckeghem M, Brutten G (2007) The KiddyCAT: Communication attitude test for preschool and kindergarten children who stutter. San Diego, CA: Plural Publishing.

7. Bernardini S, Zmarich C, Cocco L (2004) Communicative attitude of gradeschoolers who do and do not stutter. ASHA Leader. 9: 104.

8. Brutten G, Vanryckeghem M (2003) Behavior Assessment Battery: A multi-dimensional and evidence-based approach to diagnostic and therapeutic decision making for children who stutter. Belgium: Stichting Integratie Gehandicapten \& Acco Publishers.

9. Jaksic Jelcic S and Brestovci B (2000) Communication attitudes of children who stutter and those who do not. J Fluency Disord. 25: 208.

10. Ambrose N, Yairi E (1994) The development of awareness of stuttering in preschool children. J Fluency Disord. 19: 229-245.

11. Ezrati-Vinacour R, Platzky R, Yairi E (2001) The young child's awareness of stuttering-like disfluency. J Speech Lang Hear Res 44: 368-380.

12. Vanryckeghem M, Brutten G, Hernandez L (2005) The KiddyCAT: A normative investigation of stuttering and nonstuttering preschoolers' speech-associated attitude. J Fluency Disord. 30: 307-318.

13. Clark CE1, Conture EG, Frankel CB, Walden TA (2012) Communicative and psychological dimensions of the KiddyCAT. J Commun Disord 45: 223-234. 
Citation: Brce J and Vanryckeghem M (2017) Communication Attitude of Slovenian Preschool Children who do and do not Stutter. J Speech Pathol Ther 2: 124. doi:10.4172/2472-5005.1000124

Page 5 of 5

14. Vanryckeghem M, De Niels T, Vanrobayes S (2015) The KiddyCAT: A test-retest reliability investigation. Cross Cultural Communication. 11: 10-16.

15. Novšak BJ, Vanryckeghem M, Košir S, Jerman J (2015) Odnos do lastnega govora pri predšolskih otrocih, ki jecljajo. In: Devjak T (ed.) Vpliv družbenih sprememb na vzgojo in izobraževanje. Ljubljana: Pedagoška fakulteta: 205-220.

16. Vanryckeghem M, Brutten G (2015) KiddyCAT: Communication Attitude Test voor Stotterende Kleuters. Belgium: Sig.

17. Wesierska W, Vanryckeghem M (2015) A comparison of communicative attitudes among stuttering and nonstuttering Polish preschoolers using theKiddyCAT. Procedia-Social and Behavioral Sciences 193: 278-284.

18. Stokke Guttormsen LS, Kefalianos E, Naess KA (2015) Communication attitudes in children who stutter: A meta-analytic review. J Fluency Disord 46: 1-14.
19. Wesierska K, Vanryckeghem M, Jeziorczak B, Wilk B (2013) Porównanie postaw komunikacyjnych mówiacych plynnie i jakajacych sie polskojezycznych dzieci w wieku przedszkolnym. In: Ogólnopolskiej Konferencji Logopedycznej Metody i narzedzia diagnostyczne w logopedii - Warszawa.

20. Yaruss JS, Quesal RW (2006) Overall Assessment of the Speaker's Experience of Stuttering (OASES): documenting multiple outcomes in stuttering treatment. J Fluency Disord 31: 90-115.

21. Vanryckeghem M, Brutten G (2012) A Comparative investigation of the BigCAT and Erickson S-24 measures of speech-associated attitude. J Commun Disord. 45: 340-347.

22. Vanryckeghem M, Brutten G (2011) The BigCAT: A normative and comparative investigation of the communication attitude of stuttering and nonstuttering adults. J Commun Disord. 44: 200-206 